\title{
Assessing the Climate Sensitivity of the Global Terrestrial Carbon Cycle Model SILVAN
}

\author{
J. Kaduk ${ }^{1}$ and M. Heimann, \\ Max Planck Institut für Meteorologie, Bundesstr. 55, D-20146 Hamburg
}

\author{
Camera-ready Copy for \\ Physics and Chemistry of the Earth
}

Manuscript-No. OA13.2-048

Offset requests to:

J. Kaduk 


\title{
Assessing the Climate Sensitivity of the Global Terrestrial Carbon Cycle Model SILVAN
}

\author{
J. Kaduk ${ }^{1}$ and M. Heimann, \\ Max Planck Institut für Meteorologie, Bundesstr. 55, D-20146 Hamburg \\ ${ }^{1}$ Present address: Carnegie Institution of Washington, Department of Plant Biology, 290 Panama Street, Stanford, CA 94305, \\ USA
}

Received 13 June 1996 - Accepted 22 May 1997

\begin{abstract}
.
The growth rate of the atmospheric $\mathrm{CO}_{2}$ concentration exhibits interannual anomalous variations of $1-2 \mathrm{ppmV} \mathrm{yr}^{-1}$ which reflect the response of the global carbon fluxes to large scale climate fluctuations. The climate sensitivity of global carbon cycle models can be explored by the simulation of these variations. Here we test the climate sensitivity of the global terrestrial carbon cycle model SILVAN 2.3 using this approach. The model has a horizontal resolution of $0.5^{\circ}$, a $6-$ day time step and considers potential vegetation only. Important features are a model-generated water balance and physiological approaches to determine net primary productivity (NPP) and phenology. In the three sensitivity experiments SILVAN 2.3 was forced in addition to the monthly climatologies by: (A) observed temperature anomalies 1854-1993, (B) observed precipitation anomalies 1900-1993, and (C) observed anomalous temperature and precipitation as well as the atmospheric $\mathrm{CO}_{2}$ concentration increase 1765-1993. Simulated and observed anomalous $\mathrm{CO}_{2}$ fluxes into the atmosphere 1958-1993 are well correlated. The largest fraction of the modelled anomalous $\mathrm{CO}_{2}$ fluxes results from the temperature sensitivity of the physiological NPP model; the effect of the precipitation variations is relatively small. The simulated heterotrophic respiration is more sensitive to precipitation than to temperature. We discuss the extent to which the model response results additively from the anomalous $\mathrm{CO}_{2}$ fluxes generated by the temperature or precipitation anomalies only.
\end{abstract}

$\overline{\text { Correspondence to: J. Kaduk }}$

\section{Introduction}

The global terrestrial biosphere plays a vital rôle for man, who is depending on it for food, fuel, lumber and various environmental benefits. Therefore it is of considerable interest how the biosphere might react to a possible greenhouse gas especially $\mathrm{CO}_{2}$ - induced climate change and whether it will store or release relevant amounts of carbon - thus providing possibly a negative or positive feedback to climate change.

Since there is no well known equivalent in earth's history for envisaged future climate states and transition rates we have to rely on modelling the possible climate change effects. The thorough testing of models describing the global terrestrial carbon cycling with contemporary and historical data is a prerequisite for meaningful extrapolations into the future. In view of an application of global terrestrial carbon cycle models for predicting the effects of a changing climate, tests of their climate sensitivities are essential.

Here, we use the interannual fluctuations of the observed atmospheric $\mathrm{CO}_{2}$ concentration to assess the climate sensitivity of the global terrestrial carbon cycle model SILVAN on the interannual time scale (3-5 years).

\section{Methods}

The atmospheric $\mathrm{CO}_{2}$ concentration growth rate exhibits interannual anomalous variations of $2-4{\mathrm{GtC} \mathrm{yr}^{-1}}^{-1}(1 \mathrm{GtC}=$ $10^{15} \mathrm{gC}$ ) (Fig. 1). The depicted data represent smoothed monthly anomalous $\mathrm{CO}_{2}$ fluxes (expressed in $\mathrm{GtCyr}^{-1}$ ) into the atmosphere. They were derived from the atmospheric $\mathrm{CO}_{2}$ concentration data of Keeling et al. (1995) as follows. Firstly a the long term $\mathrm{CO}_{2}$ uptake by the oceans was determined from a simulation with the ocean model HAMOCC3 (Maier-Reimer (1993), Kurz (1993), Heimann and MaierReimer (1996)) forced by the observed increase of the atmospheric $\mathrm{CO}_{2}$ concentration since preindustrial times. Secondly, the long term $\mathrm{CO}_{2}$ induced uptake of the terrestrial biosphere $S_{b i o}(t),(t$, time), was assumed to be proportional 


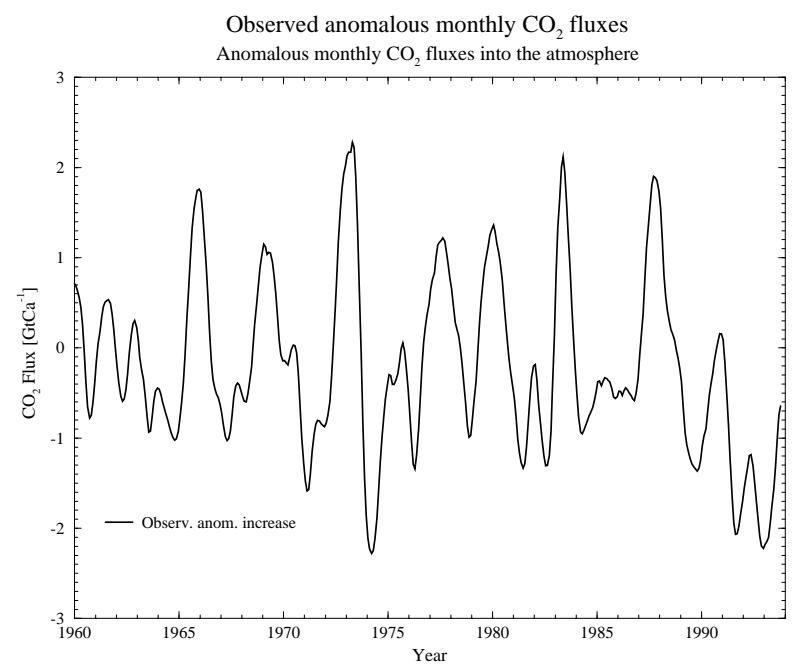

Fig. 1. Observed, globally integrated monthly anomalous $\mathrm{CO}_{2}$ fluxes into the atmosphere derived from the atmospheric $\mathrm{CO}_{2}$ concentration data of Keeling et al. (1995). The long term $\mathrm{CO}_{2}$ uptake by the oceans and the terrestrial biosphere as well as industrial and land use induced $\mathrm{CO}_{2}$ emissions were subtracted from the observed increase of the global atmospheric $\mathrm{CO}_{2}$ concentration. The remaining anomalous monthly fluxes have been smoothed by suppressing frequencies higher than approximately $1 /(3$ years). For further details see the section on methods.

to the increase of the atmospheric $\mathrm{CO}_{2}$ concentration since 1765: $S_{b i o}(t)=\gamma\left(C O_{2}(t)-C O_{2}(1765)\right)$. $\gamma$ was determined such that the atmospheric $\mathrm{CO}_{2}$ budget of the 1980's is balanced (Schimel et al., 1995). Thus, this long term carbon flux $S_{b i o}$ from the atmosphere to the biosphere was assumed to be climate and land use independent. These $\mathrm{CO}_{2}$ fluxes into ocean and terrestrial biosphere define together with estimates of the annual $\mathrm{CO}_{2}$ emissions from industrial sources (Marland et al., 1994) and from changes in landuse (Houghton, 1994) the long term growth trend of the atmospheric $\mathrm{CO}_{2}$ concentration. Thirdly, anomalous exchanges of the atmospheric $\mathrm{CO}_{2}$ were computed by subtracting the long term growth trend from the seasonally adjusted average of the Mauna Loa and South Pole records (Keeling et al., 1995). Finally the anomalous $\mathrm{CO}_{2}$ fluxes into the atmosphere as depicted in Fig. 1 were obtained by smoothing these exchanges with a lowpass binomial filter, suppressing frequencies higher than approximately $1 / 3 \mathrm{yr}^{-1}$. The anomalous variations reflect the response of the global carbon fluxes to large scale climate fluctuations (Keeling et al., 1995). For example, the so called El Niño - Southern Oscillation (ENSO) events - large scale climate anomalies in the Pacific - e.g. in the years $1973 / 74,1982 / 83$ and $1987 / 88$ are clearly discernible.

SILVAN is a global terrestrial carbon cycle model with $0.5^{\circ}$ horizontal resolution, six carbon reservoirs per grid-element and a daily to monthly time step. It decribes potential vegetation only. The standard version of the model is forced with mean monthly temperature, cloudiness, daily temperature amplitude, monthly precipitation and the mean annual atmospheric $\mathrm{CO}_{2}$ concentration. Further important features

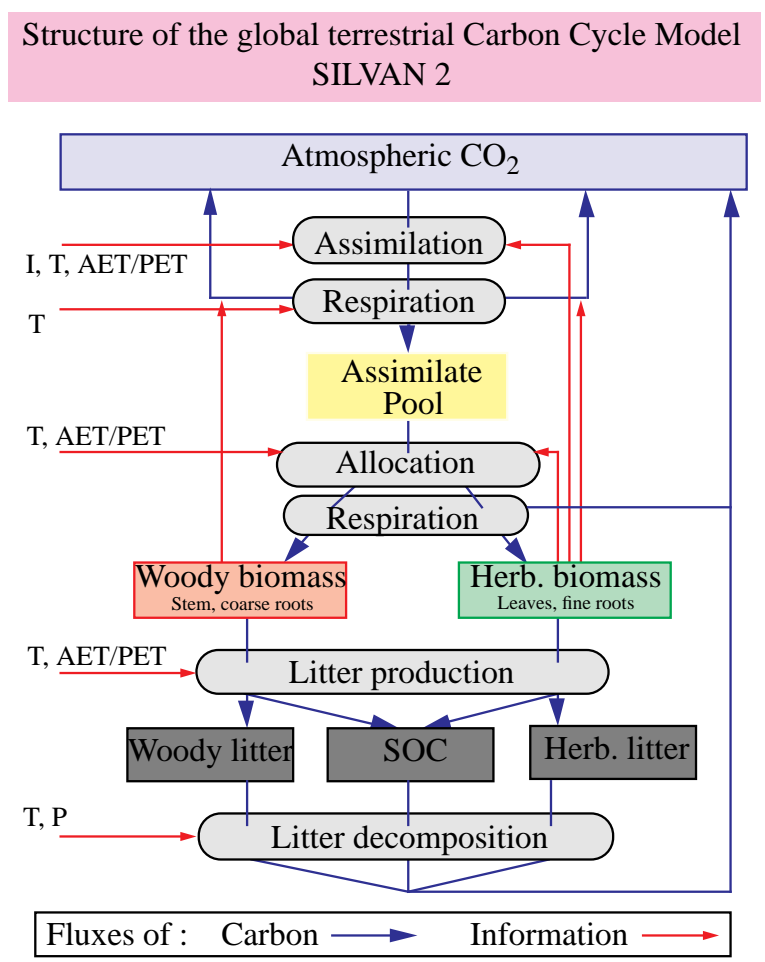

Fig. 2. Structure of the carbon cycle in SILVAN 2.3 for each grid-element. The model considers six reservoirs of carbon (rectangulars) - assimilates, woody and herbaceous carbon in the living plants and woody and herbaceous litter and soil organic carbon (SOC) in the dead terrestrial biosphere. The simulated processes (ovals) are: assimilation (influenced by light (I), temperature $(\mathrm{T})$, and the ratio of actual to potential evapotranspiration (AET/PET)), maintenance respiration (depending on $\mathrm{T}$ ), allocation of assimilates into structural components (depending on $\mathrm{T}$ and AET/PET), growth respiration (a fixed fraction of the allocated material and independent of environmental influences), litter production (defined from $\mathrm{T}$ and AET/PET) and finally litter decomposition, i.e. heterotrophic respiration (depending on $\mathrm{T}$ and precipitation $(\mathrm{P}))$.

of the model are an interactively simulated water cycle on a daily time step, a physiologically based approach for the determination of NPP following Farquhar et al. (1980), climate driven phenology and carbon allocation from the assimilate to herbaceous and woody carbon pools. Heterotrophic respiration is formulated according to Esser (1991). The structure of the carbon cycle in the model is depicted in fig. 2. With 340 ppmv atmospheric $\mathrm{CO}_{2}$ the model predicts at steady state a global NPP of $57.3 \mathrm{GtCyr}^{-1}$, gross primary productivity (GPP) of $121.5 \mathrm{GtCyr}^{-1}$, maintenance respiration of $46.4 \mathrm{GtCyr}^{-1}$ and growth respiration of 17.8 $\mathrm{GtCyr}^{-1}$. Global carbon mass in assimilate, living herbaceous and woody reservoirs are 43.5, 12.7 and $1022 \mathrm{GtC}$ and in herbaceous and woody litter and soil organic carbon reservoirs 33.3, 81 and $1867 \mathrm{GtC}$ respectively. A complete model description and other results can be found in Kaduk (1996). 
For the experiments described here the latest version of the model, 2.3, was run with a 6-day time step of the carbon cycle using a prescribed biome distribution as defined from the BIOME 1 model of Prentice et al. (1992). In addition to the standard climatologies (Cramer and Leemans (1994)) the model was forced in the three sensitivity experiments with:

A observed mean monthly temperature anomalies 1854 1993 (Jones et al. (1986), updated pers. comm.),

B monthly precipitation anomalies 1900-1993 derived from observed preciptation data (Hulme, 1995)

C observed monthly climate anomalies as in A and B and observed mean annual atmospheric $\mathrm{CO}_{2}$ concentration 1765-1993 (IPCC 1994, 1995).

Data gaps in the $4^{\circ} \times 5^{\circ}$ horizontal grid of monthly temperature anomalies were filled spatially by applying a Laplace filling technique; the missing data in the precipitation data set were reconstructed by spatial interpolation and rescaling to the standard climatologies assuming a Weibull distribution. The resulting global climate anomaly data sets have a monthly time resolution. The anomaly data were subsequently interpolated to the $0.5^{\circ}$ grid of the model and added to the standard climatology in order to drive the model.

The $\mathrm{CO}_{2}$ flux time series generated by the model simulations were detrended, and the mean seasonal cycle subtracted. SILVAN simulates an increase in the seasonal amplitude of atmospheric $\mathrm{CO}_{2}$ when forced with the observed increase of the atmospheric $\mathrm{CO}_{2}$ concentration (Kaduk and Heimann, 1995). To remove this effect from the results of experiment $\mathrm{C}$ we used the results of an additional model run in which the prescribed atmospheric $\mathrm{CO}_{2}$ concentration was increasing but the climate was held constant (Kaduk, 1996). The increase in the seasonal cycle derived from the additional experiment was subtracted from the results of experiment $\mathrm{C}$.

Finally, the simulated $\mathrm{CO}_{2}$ fluxes obtained from the experiments $\mathrm{A}, \mathrm{B}$, and $\mathrm{C}$ were lowpass filtered in the same way as the observations.

\section{Results}

Figure 3 displays the simulated global anomalous $\mathrm{CO}_{2}$ fluxes into the atmosphere together with the observations. In general the model reproduces the observed anomalous $\mathrm{CO}_{2}$ fluxes into the atmosphere quite well. The largest part of the simulated global anomalous $\mathrm{CO}_{2}$ fluxes is caused by the temperature response of the model. The precipitation anomalies induce only small fluctuations and seem of minor importance. Indeed, as seen in the lagged correlations (Fig. 4) the precipitation anomalies only marginally tend to improve the correlation between observation and simulation. The simulated anomalous $\mathrm{CO}_{2}$ fluxes of experiment $\mathrm{C}$ are found to be almost equal to the sum of the results of experiments $\mathrm{A}$ and B. Clearly this should always be the case if temperature and precipitation variations are small as seen from a Taylor expansion.

A latitudinal comparison with observations is displayed in Fig. 5. Conway et al. (1994) constructed from atmospheric

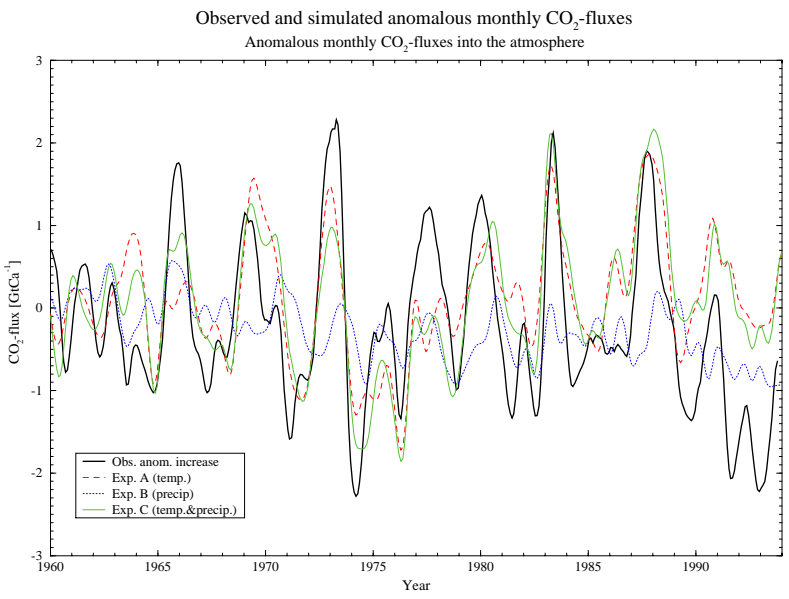

Fig. 3. Observed and simulated global anomalous $\mathrm{CO}_{2}$ fluxes into the atmosphere. Note, the model simulations represent only the climate induced anomalous contribution from the terrestrial biosphere whereas the observations possibly reflect additional anomalous contributions from other components of the global carbon cycle.

$\mathrm{CO}_{2}$ concentration measurements 1981-1993 of the Climate Monitoring and Diagnostics Laboratory Global Air Sampling Network the zonally averaged field of the interannual atmospheric $\mathrm{CO}_{2}$ growth rate (Fig. 5a). Figure 5b depicts the simulated anomalous biospheric $\mathrm{CO}_{2}$ fluxes to the atmosphere from experiment $\mathrm{C}$ averaged over $15^{\circ}$ latitudinal zones. The mean global annual increase 1981-1993 of $\approx 1.5 \mathrm{ppmv}$ $\mathrm{yr}^{-1}$ as deduced by Conway et al. (1994) has been added to the simulation results to increase the comparability of the observed interannual growth rate and the simulated anomalous $\mathrm{CO}_{2}$ fluxes.

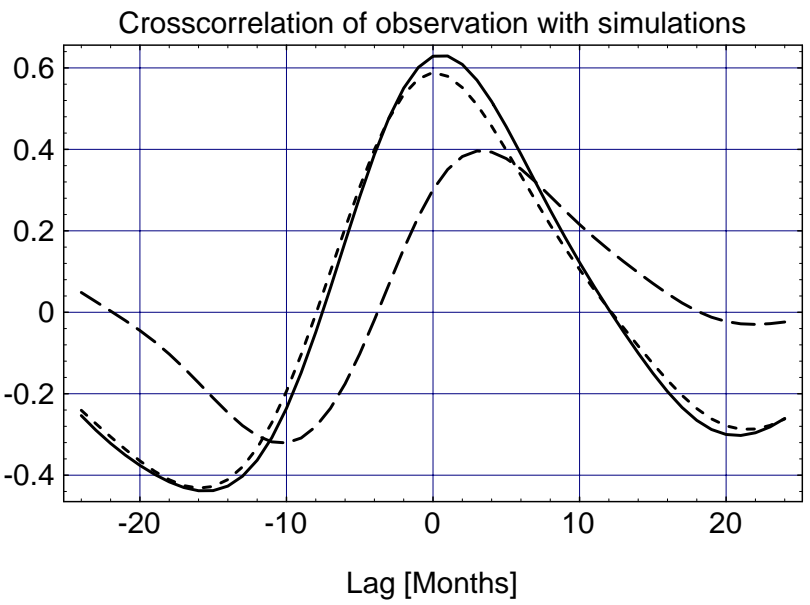

Fig. 4. Lagged cross-correlation between observed and simulated anomalous $\mathrm{CO}_{2}$ fluxes into the atmosphere from exp. A (- -), B (--) and $\mathrm{C}(-)$.

Clearly, the atmospheric observations reflect variations in terrestrial and possibly also oceanic $\mathrm{CO}_{2}$ sources and furthermore they are smoothed by atmospheric transport. Nevertheless, SILVAN reproduces the most prominent anomalous variations of the atmospheric $\mathrm{CO}_{2}$ concentration - in particular the two strong ENSO events 1982/83 and 1987/88. 

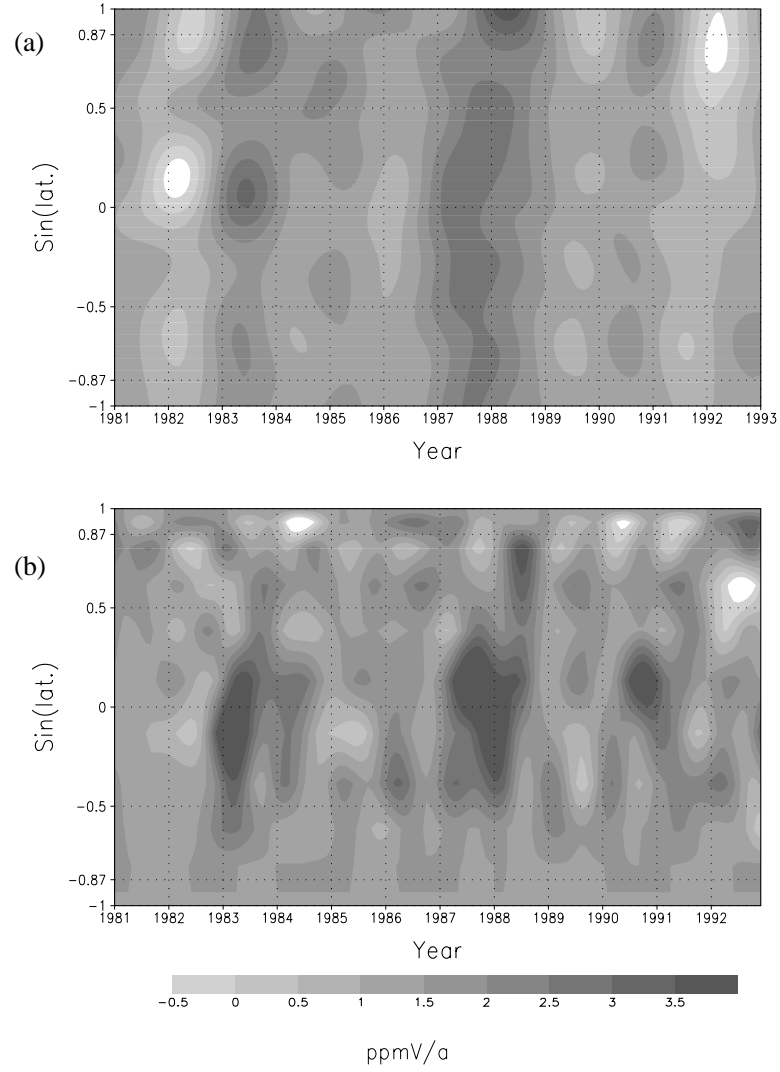

Fig. 5. Observed and simulated growthrate of the zonally averaged atmospheric $\mathrm{CO}_{2}$ concentration: a) observations from the atmospheric $\mathrm{CO}_{2}$ concentration measurements 1981-1993 of the Climate Monitoring and Diagnostics Laboratory Global Air Sampling Network Conway et al. (1994). b) simulated anomalous biospheric $\mathrm{CO}_{2}$ fluxes to the atmosphere from experiment $\mathrm{C}$ in $15^{\circ}$ latitudinal zones added to the mean global annual increase 1981-1993 of 1.5 ppmv yr $^{-1}$.

The strong negative anomaly in the high northern latitudes 1991/92 - presumably related to the Pinatubo volcano eruption and subsequent cooler and wetter climate - is also reproduced but simulated somewhat too late and too small. The largest fraction of the simulated anomalous global fluxes shown in Figure 3 originates in the tropics. Figure $6 \mathrm{~b}$ shows that the simulated anomalous fluxes result mainly from the temperature response of the physiologically based NPP model. The sensitivity of global NPP to precipitation is only about a third of the temperature response. On the other hand, global heterotrophic respiration reacts quite sensitive to precipitation (Fig. 6c).

Globally, temperature and precipitation over land tend to be anti-correlated on the ENSO time scale (Fig. 6a), where the global signal is primarily dominated by the variations in the tropics. This leads to a correlated behaviour of the two biospheric fluxes, NPP and heterotrophic respiration: if temperature increases, NPP tends to decrease. If at the same time precipitation decreases, heterotrophic respiration will be diminished, too.

These correlated effects of the climate anomalies on NPP and heterotrophic respiration lead to a partial cancellation and
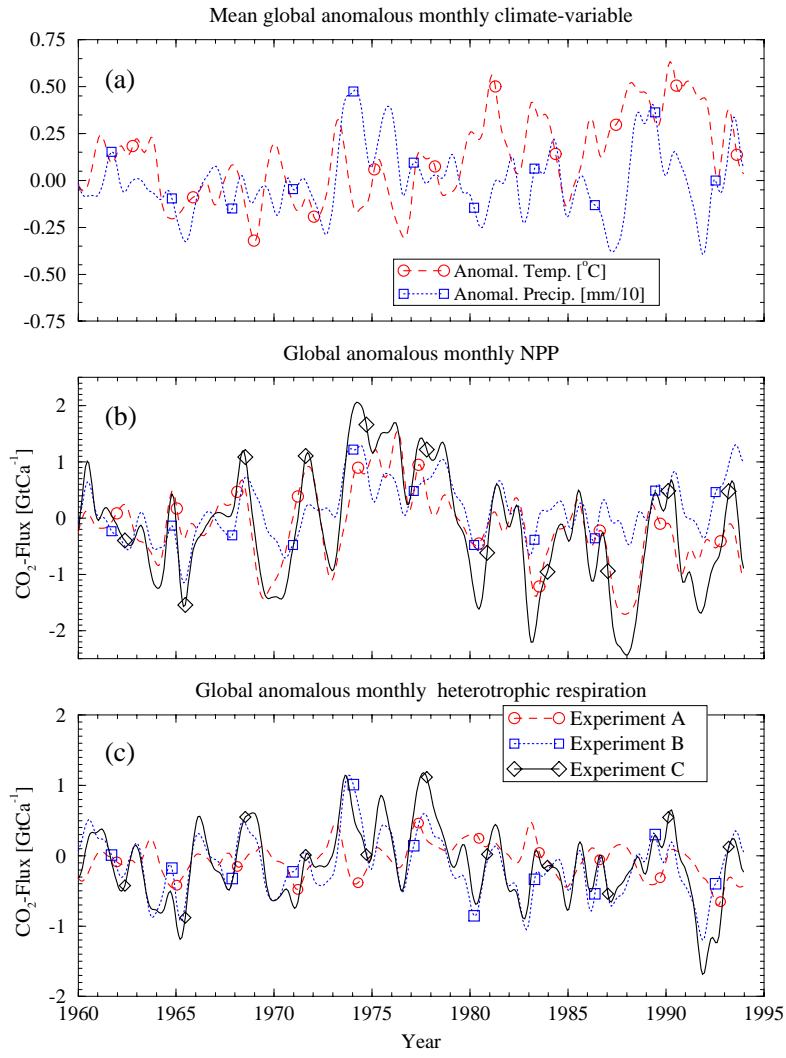

Fig. 6. Climate anomalies and simulated anomalous biospheric $\mathrm{CO}_{2}$ fluxes from the experiments: a) lowpass filtered observed global mean monthly climate anomalies over land, b) global anomalous NPP from the three experiments: A (- -), B (...) and C (-), and c) global anomalous heterotrophic respiration from the three experiments: $\mathrm{A}(--), \mathrm{B}(\ldots$.$) and \mathrm{C}(-)$.

thus result in a damped climate sensitivity of the net biospheric flux.

The linear behaviour of the modelled anomalous net biospheric flux on the global scale with respect to the two climate forcing factors can tentatively be explained by their different impacts on NPP and heterotrophic respiration. Temperature fluctuations primarily influence NPP (experiment A), while precipitation anomalies most strongly affect heterotrophic respiration (experiment B). To first order the anomalous flux in experiment $C$ therefore equals essentially the anomalous NPP from experiment A plus the anomalous heterotrophic respiration from experiment B. E.g. in 1982/83 the anomalous flux deduced from experiment $\mathrm{C}$ is approximately equal to the sum of the anomalous temperature induced NPP from experiment $\mathrm{A}$ and the precipitation induced anomalous heterotrophic respiration from experiment $\mathrm{B}$.

\section{Discussion}

The observed anomalous $\mathrm{CO}_{2}$ fluxes into the atmosphere reflect also contributions from other sources than the climate response of vegetation. Keeling et al. (1995) deduced from their observations of the atmospheric ${ }^{13} \mathrm{C} /{ }^{12} \mathrm{C}$ isotope ratio 
data anomalous biospheric $\mathrm{CO}_{2}$ fluxes on the ENSO time scale. The simulated fluxes in the present study are quite well in phase with the fluxes derived by Keeling et al. (1995) from their isotope data, however the amplitude of the simulated fluxes is smaller by about a factor of two. This contrasts with a similar experiment reported by Kindermann et al. (1996), who, using a different terrestrial biosphere model (the Frankfurt Biosphere Model (FBM)) and different climate forcing data, deduce anomalous biospheric $\mathrm{CO}_{2}$ fluxes with an amplitude comparable to the one derived from the deconvolution of Keeling et al. (1995).

Although the deductions from the ${ }^{13} \mathrm{C} /{ }^{12} \mathrm{C}$ observations are not undisputed (Francey et al., 1995) and reflect the effects from other biospheric $\mathrm{CO}_{2}$ sources as well (e.g. anomalous wildfire activity and biomass burning, Jiang and Yung (1996)), the ${ }^{13} \mathrm{C} /{ }^{12} \mathrm{C}$ inferred biospheric $\mathrm{CO}_{2}$ fluxes suggest that the overall climate sensitivity of SILVAN is somewhat too small.

In contrast to the results reported here, Dai and Fung (1993) found that global NPP was more sensitive to precipitation than to temperature while Kaduk and Heimann (1994) found that the net carbon flux was also more sensitive to precipitation than to temperature variations.

However, these latter studies employed different versions of the MIAMI model (Lieth, 1975) which is based on an empirical relationship of an assumed steady state vegetation and the long term climate mean. This relationship has been determined from NPP measurements of natural vegetation more or less in equilibrium with climate and the long term mean climate at the measurements sites. The MIAMI model therefore emphazises more the processes leading to the establishment of a vegetation type adapted to the prescribed climate including all involved processes, as e.g. competition, rather than the processes which cause short term fluctuations in carbon fluxes.

Thus, simulations using the MIAMI model implicitly contain the assumption that the vegetation type is always adapted to the prevailing climate whereas SILVAN describes vegetation processes as a function of the climate with a fixed, prescribed vegetation distribution. Therefore if e.g. a wet tropical forest experiences a dry year, the MIAMI model would simulate NPP approriate for a seasonal tropical forest and the modelled climate response of the model is driven by the fact that drier regions have lower NPP than wet regions. On the other hand, SILVAN would simulate the NPP of a rain forest stressed by soil water deficiencies.

Furthermore, a considerable part of the precipitation sensitivity of the net flux reported in the 1994 study (Kaduk and Heimann, 1994) was induced by the simulated heterotrophic respiration. In that study the same formulations for heterotophic respiration were used as in SILVAN which appears to be quite precipitation sensitive. In any case the anomalous net fluxes deduced in the 1994 study equal only about those of experiment B in the current study and are thus much too small.

In SILVAN high temperatures can lead via increased evapotranspiration to a soil water deficit just as decreased pre- cipitation. However, the effects of precipitation fluctuations on NPP are buffered by the modelled soil moisture reservoir. Additionally, high temperatures result in decreased quantum efficiency of photosynthesis and increased autotrophic respiration. Hence both processes lead to a reduction of NPP under higher temperatures.

Interestingly, a preliminary evaluation indicates that in the FBM the simulated net biospheric flux might be dominated by the temperature sensitivity of autotrophic respiration (Kindermann et al., 1996) and direct effects on GPP are of minor importance. In contrast in SILVAN there are pronounced variations in GPP in response to temperature fluctuations.

This highlights that from a system analytic point of view, modelling well defined processes is preferable to the employment of an highly integrated empirical model, since this allows to trace the fluctuations in the simulation results to well defined causes.

The fact that the anomalous net fluxes simulated by SILVAN are possibly still too small is also supported by the fact that heterotrophic respiration is generally believed to be more temperature sensitive than simulated here (Raich and Potter, 1995). This could indicate that the regression based rates for heterotrophic respiration of Esser (1991) as implemented in SILVAN might not be suited for simulations on interannual timescales with monthly or more rapidly varying climate forcing, although SILVAN seems to simulate reasonably well heterotrophic respiration, at least in the temperate zone (Heimann et al. (1997), Kaduk and Heimann (1996), Kaduk (1996) discuss the simulated seasonal cycle of atmospheric $\mathrm{CO}_{2}$, in Kaduk (1996) modelled monthly heterotrophic respiration is compared to observations by Dörr and Münnich (1987)). However, the too weak biospheric $\mathrm{CO}_{2}$ sink simulated in the northern hemisphere following the Pinatubo eruption might be attributed at least in part to a limited suppression of heterotrophic respiration by a cooler climate in high northern latitudes.

In summary, the largest fraction of the modelled anomalous $\mathrm{CO}_{2}$ fluxes results from the temperature sensitivity of the physiological NPP model. The influence of precipitation variations is weaker and impacts the simulated heterotrophic respiration more strongly than NPP.

\section{Conclusion}

The climate sensitivity of global terrestrial carbon cycle models can be explored by simulations of the anomalous, climate driven net $\mathrm{CO}_{2}$ fluxes to the atmosphere and comparing the results to the observed anomalous growthrate of the atmospheric $\mathrm{CO}_{2}$ concentration. Using this approach, the large scale, anomalous $\mathrm{CO}_{2}$ fluxes into the atmosphere as simulated by SILVAN 2.3 forced by observed climate are found to be well correlated with the observations on the ENSO time scale. However, the model fails to reproduce the observed strongly enhanced $\mathrm{CO}_{2}$ uptake during the post-Pinatubo period (1992-93).

This test cannot be conclusive, since the atmospheric ob- 
Journal: Physics and Chemistry of the Earth

MS No.: OA13.2-048

First author: Kaduk

servations include additional sources of variability, such as changes of air-sea $\mathrm{CO}_{2}$ fluxes, which, at present, cannot unambiguously be determined. Nevertheless, a preliminary assessment can be made considering processes and sensitivities. However, the comparison of different biosphere models shows that there seems to be no general agreement concerning the relative importance of the different processes involved in biospheric carbon uptake.

Clearly further tests are needed to provide a more comprehensive assessment of the climate sensitivity of SILVAN on the interannual timescale. Possibles candidates include the explicit simulations of the carbon or oxygen isotopes in $\mathrm{CO}_{2}$. Alternative tests may be provided by forcing the processes involved in simulated NPP (photosynthesis and autotrophic respiration) and heterotrophic respiration separately with observed climate and comparing the results to long term observations from local eddy-correlation flux measurements.

At least in the case of the the simulations reported here, a stronger sensitivity of heterotrophic respiration to temperature would presumably increase the magnitude of the simulated anomalous $\mathrm{CO}_{2}$ fluxes into the atmosphere.

Acknowledgements. This work was supported in part by the Commision of the European Union under contracts ENV4-CT95-0116 and EN5V-CT920120 (European Study of Carbon in the Oceans, Biosphere and Atmosphere (ESCOBA): Atmosphere Section). Computing support was provided by the Deutsches Klimarechenzentrum (DKRZ). The authors thank to anonymous reviewers for their helpful comments.

\section{References}

Conway, T. J., Tans, P., Waterman, L., Thoning, K., Buanerkitzis, D., Masarie, K., and Zhang, N., Evidence for interannual variability of the carbon cycle from the NOAA-CMDL global air sampling network, $J$. Geophys. Res., 99D, 22,831-22,855, 1994.

Cramer, W. P. and Leemans, R., The IIASA database for mean monthly values of temperature precipitation, and cloudiness on a global terrestrial grid, updated from Leemans and Cramer (1991), pers. comm., 1994.

Dai, A. and Fung, I. Y., Can climate variability contribute to the missing sink?, Global Biogeochemical Cycles, 7(3), 599-609, 1993.

Dörr, H. and Münnich, K. O., Annual variation in soil respiration in selected areas of the temperate zone, Tellus, (37B), 114-121, 1987.

Esser, G., Osnabrück biosphere model: construction, structure, results, in Modern Ecology: Basic and Applied Aspects, edited by G. Esser and D. Overdieck, Elsevier, Amsterdam, New York, 1991.

Farquhar, G. D., von Caemmerer, S., and Berry, J. A., A biochemical model of photosynthetic $\mathrm{CO}_{2}$ assimilation in leaves of $\mathrm{C}_{3}$ species., Planta, (149), 78-90, 1980.

Francey, R. J., Tans, P. P., Allison, C. E., Enting, I. G., White, J. W. C., and Troller, M., Changes in oceanic and terrestrial carbon uptake since 1982, Nature, 373, 326-330, 1995.

Heimann, M. and Maier-Reimer, E., On the relations between the oceanic uptake of $\mathrm{CO}_{2}$ and its carbon isotopes, Global Biogeochemical Cycles, 10(1), 89-110, 1996.
Heimann, M., Esser, G., Haxeltine, A., Kaduk, J., Kicklighter, D. W., Knorr, W., Kohlmaier, G. H., McGuire, A. D., Melillo, J., Moore, B., Otto, R. D., Prentice, I. C., Sauf, W., Schloss, A., Sitch, S., Wittenberg, U., and Würth, G., Evaluation of terrestrial carbon cycle models through simulations of the seasonal cycle of atmospheric $\mathrm{CO}_{2}$. First results of a model intercomparison study., Global Biogeochemical Cycles, 1997.

Houghton, R. A., Changes in terrestrial carbon over the last 135 years., in The Global Carbon Cycle, edited by M. Heimann, vol. I15 of NATO ASI series, Springer, Berlin Heidelberg, 1994.

Hulme, M., A historical monthly precipitaion dataset for global land areas from 1900 to 1994, Supported by the UK Department of the Environment Contract PECD7/12/78, Climate Reseach Unit, University of East Anglia, Norwich, UK., 1995.

IPCC 1994, Summary for policymakers - radiative forcing of climate change, 1995.

Jiang, Y. and Yung, Y. L., Concentrations of tropospheric ozone from 1979 to 1992 over tropical pacific south america from TOMS data, Science, 272, 714-716, 1996.

Jones, P. D., Raper, S. C. B., Cherry, B. S. G., Goodess, C. M., Wigley, T. M. L., Santer, B., Kelly, P. M., Bradley, R. S., and Diaz, H. F., A global grid point surface air temperature data set: 1851-1984, NDP 020, Carbon Dioxide Information Centre, Oak Ridge National Laboratory, Oak Ridge, Tennessee, 1986.

Kaduk, J., Simulation der Kohlenstoffdynamik der globalen Landbiosphäre mit SILVAN - Modellbeschreibung und Ergebnisse, Ph.D. thesis, MPI für Meteorologie, Hamburg, 1996.

Kaduk, J. and Heimann, M., The climate sensitivity of the Osnabrück biosphere model on the ENSO time scale., Ecological Modelling, 75/76, 239-256, 1994.

Kaduk, J. and Heimann, M., Simulation of the biospheric contribution to the seasonal cycle of atmospheric $\mathrm{CO}_{2}$ by a physiologically based global biosphere model, Annalen der Meteorologie, 31, 414-415, 1995.

Kaduk, J. and Heimann, M., A prognostic phenology scheme for global terrestrial carbon cycle models, Clim Res, 6(1), 1-19, 1996.

Keeling, C. D., Whorf, T. P., Wahlen, M., and van der Plicht, J., Interannual extremes in the rate of rise of atmospheric carbon dioxide since 1980, Nature, 375, 666-670, 1995.

Kindermann, J., Würth, G., Kohlmaier, G., and Badeck, F.-W., Interannual variation of carbon exchange fluxes in terrestrial ecosystems, Global Biogeochemical Cycles, 10(4), 737-755, 1996.

Kurz, K., Zur saisonalen Variabilität des ozeanischen Kohlendioxidpartialdrucks, Ph.D. thesis, MPI für Meteorologie, Hamburg, 1993.

Leemans, R. and Cramer, W. P., The IIASA database for mean monthly values of temperature, precipitation, and cloudiness on a global terrestrial grid, Research Report RR-91-18, IIASA, 1991.

Lieth, H., Modelling the primary productivity of the world, in Primary Productivity of the Biosphere, edited by H. Lieth and R. Whittaker, Springer, Berlin Heidelberg New York, 1975.

Maier-Reimer, E., Geochemical cycles in an ocean general circulation model. Preindustrial tracer distributions, Global Biogeochemical Cycles, 7(3), 645-677, 1993. 
Journal: Physics and Chemistry of the Earth

MS No.: OA13.2-048

First author: Kaduk

Marland, G., Andres, R. J., and Boden, T. A., Global, regional, and national $\mathrm{CO}_{2}$ emissions., in Trends'93: A Compendium of Data on Global Change., edited by T. A. Boden, D. P. Kaiser, R. J. Sepanski, and F. W. Stoss, vol. ORNL/CDIAC-65, pp. 505-584, Carbon Dioxide Information Analysis Center, Oak Ridge National Laboratory, Oak Ridge, Tenn., USA, 1994.

Prentice, I. C., Cramer, W., Harrison, S. P., Monserud, R. A., and Solomon, A. M., A global biome model based on plant physiology and dominance, soil properties and climate, Journal of Biogeography, (19), 117-134, 1992.

Raich, J. W. and Potter, C. S., Global patterns of carbon dioxide emsissions from soils, Global Biogeochemical Cycles, 9(1), 23-36, 1995.

Schimel, D., Enting, I. G., Heimann, M., Wigley, T. M. L., Raynaud, D., Alves, D., and Siegenthaler, U., $\mathrm{CO}_{2}$ and the carbon cycle, in Climate Change 1994, edited by J. T. Houghton et al., pp. 35-72, CUP, Cambridge, UK, 1995. 